\title{
Model for Project-Based Community Engagement
}

\author{
Paul A. Leidig, P.E. \\ $\mathrm{PhD}$ Student, School of Engineering Education \\ Purdue University \\ West Lafayette, IN 47907 \\ pleidig@purdue.edu \\ William C. Oakes, P.E. \\ 150th Anniversary Professor, Professor of Engineering Education \\ Director, EPICS Program \\ Purdue University \\ West Lafayette, IN 47907 \\ oakes@purdue.edu
}

\begin{abstract}
Community engagement experiences in STEM fields are typically project-based, which introduces components and considerations not explicitly addressed by models commonly used in community-engaged learning more broadly. This paper is a narrative of how we reflected on current models, developed a new one for project-based community engagement experiences, and where we see it being useful into the future. While existing models can be useful for STEM-based project teams, project-based engagement raises further questions and presents additional features, such as the existence of the dual value generators of both the project deliverable and project process. We concentrated on providing a macroscopic view of project-based community engagement to organize aspects of a program and maximize positive features while managing resources. The visual model has been developed to facilitate reflection on program design, development, operation, and assessment. It can facilitate intentional consideration, definition, and organization of stakeholders, project deliverables, project process, resources input, and value produced. We foresee several potential uses for this model as a conceptual framework and practical tool for community engagement experiences and programs.
\end{abstract}

Index Terms - community engagement, community-engaged learning, model, project-based

\section{INTRODUCTION}

Community-engaged learning, also known as service-learning, is the intentional integration of academic learning and participant development with work that supports the greater good within our local, national, or global communities. The integration is intended to enhance the learning of core academic content, address needs within the community, and give participants broader learning opportunities about themselves and society at large. Community engagement has been integrated into the portfolio of pedagogies within a broad range of disciplines in higher education that span the liberal arts as well as the science, technology, engineering, and mathematical (STEM) fields. As the pedagogy gained acceptance within higher education, diverse models emerged ${ }^{i}$. The American Association for Higher Education showed the breadth of integration by publishing an 18-volume series on disciplinary examples of service-learning, including a volume on engineering ${ }^{\text {ii }}$. 
International Journal for Service Learning in Engineering, Humanitarian Engineering and Social Entrepreneurship Vol. 16, No. 2, pp. 1-13, Fall 2021

ISSN 1555-9033

The pedagogy generally has five key ideal characteristics, as listed below ${ }^{\text {iii }}$. While some applications have fallen short of these aspirations in practice and the design of some programs have excluded one or more of the elements, they are all important while striving for excellence in participant learning and community partnerships.

1. Engagement opportunities that meet the needs of an underserved segment of society and/or contribute to efforts for the common good of the local, regional, or global community.

2. Academic connection between the engagement and the subject material of a course.

3. Reciprocal partnerships where the community members, students, faculty, and other partners each contribute to the experiences and benefit from the collaboration.

4. Mutual learning among all stakeholders, built on a foundation of respect.

5. Reflection, a vital component, where participants are intentionally guided through activities to reflect upon the work being performed, the processes by which the work is accomplished, the implications of the experience on the community and themselves, and how to operationalize learning from these new understandings in the future.

In the early 2000's, the terms used to describe this pedagogy began to move away from the phrase service-learning. This was due in part to the word service implying a hierarchical structure and not reflecting the reciprocal relationship paradigm. Community-engaged learning and community-based learning have become more common in many arenas, although all are still used in some settings. The American Society for Engineering Education (ASEE) uses the name community engagement as the umbrella term for the pedagogical approach and this title will be used within this paperiv.

The pedagogy has proven to have many benefits for students and the community partners ${ }^{v, v i}$. Research has shown benefits across a broad range of dimensions important to higher education. Eyler and Giles found that community engagement students learned more, were motivated to work harder than in traditional classes, and reported a deeper understanding of subject matter, understanding complexity of social issues and being able to apply material they learned in class to real problems ${ }^{\text {vii }}$. They state:

...(a) phenomenon occurs when students are able to marshal a body of knowledge to solve problems presented in class but fail even to see a problem, much less the relevance of what has been learned, in a different setting. The new situation does not provide the cues associated with what has been learned; the "key words" from the classroom are not present in the wider environment. A service-learning student will have more ways to access this understanding. ${ }^{\text {viii }}$

Astin et al. studied more than 22,000 undergraduates and found higher college grade point averages, critical thinking skills, and writing skills for participants in community engagement courses $^{\text {ix }}$. In particular, they cited the impact of course-based community engagement above generic community service that was done outside of class.

Within engineering in particular, studies have shown benefits in developing the broad professional skills including teamwork and communication $^{\mathrm{x}}$, becoming self-directed and life- 
International Journal for Service Learning in Engineering, Humanitarian Engineering and Social Entrepreneurship Vol. 16, No. 2, pp. 1-13, Fall 2021

ISSN 1555-9033

long learners ${ }^{\mathrm{xi}}$, and developing design skills $\mathrm{s}^{\mathrm{xii}}$. Community-engaged learning has been shown to increase student retention especially among students who participate in the first years of their

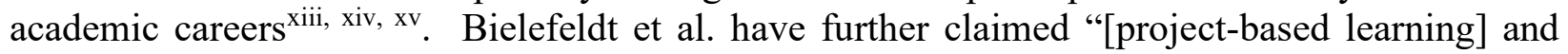
[project-based community engagement] are both effective pedagogies to achieve a broad array of core knowledge and skills that are critical for engineers" context of community engagement also aligns with research in diversity and has shown positive impacts, especially in regards to gender ${ }^{\mathrm{xvii}}$.

Community-engaged learning has become more accepted within engineering over the last two decades as evidenced by the creation and growth of the Community Engagement Division of ASEE. However, much of the early work in community engagement grew from fields where engagement experiences involved students spending time in the community or with agencies directly serving the community. These experiences can be described as placement-based. Nearly $90 \%$ of the experiences captured by Eyler and Giles in their book Where's the Learning in Service-Learning? used this placement-based approached ${ }^{\text {xviii. }}$. In many cases, such placements and direct interactions are assumed to be part of the pedagogy, with some institutions including a criterion of number of hours spent in the community for courses to be counted as communityengaged learning. Likewise, many of the models that can be used by engagement teams for creating new or refining existing programs align with the placement-based approach.

A challenge for STEM faculty and their partners is that placement-based engagement is not the dominant mode in these fields. More typically in STEM and engineering in particular, students are engaged in a project-based experiences where a significant portion of the value to the community partner results from delivering a physical artifact, piece of software, plan, design, or the like. Such endeavors may and often do include some time in the community, but that time is typically spent understanding the context and building relationships that facilitate the project work, which is conducted primarily through iterations of alternating collaborative communication and independent efforts by the various stakeholder groups. The project orientation provides distinct constraints and considerations as a program seeks to maximize positive impact among the stakeholders while managing the resources expected to be contributed by each of them. However, there are no widely used models specifically for such project-based engagement.

This paper is a narrative of how we reflected on currently available models, developed a new one for the specific subset of project-based community engagement programs, and where we see it being useful into the future. The work is inevitably colored by the particular backgrounds of its authors in engineering community engagement, but we believe that it is applicable to a wide set of programs. The first author has over fifteen years of experience in project-based community engagement, serving and leading in various roles from the positions of community member, student participant, professional volunteer, and course instructor. The second author has thirtyfive years of experience in community service and engagement as a professional and for twentyfive years as a faculty member who directs a large multi-institution community-engaged design program, having facilitated more than 100 teacher and faculty workshops as well as published more than 100 refereed papers on the topic.

For the purpose of this paper, the community-engaged learning segment of the community engagement space we are discussing is understood to involve students in some way as one of the main stakeholder groups, whether that be in a curricular experience, co-curricular pursuit, or extra-curricular activity. However, broader applications may also be possible. 


\section{EXISTING Models}

Several existing models have served areas of the service-learning and community engagement space well over the past decades. One model looks at the words of service-learning and seeks a balance between service-based impact and academic learning ${ }^{x i x}$. Table I illustrates the variations within this balance through the emphasis with capitalizations and separation or linkage with the hyphen. The model can be used to assess approaches looking at benefits for student learning and value to the community.

\section{TABLE I}

\section{A SERVICE AND LEARNING TYPOLOGY ${ }^{\mathrm{xx}}$}

\begin{tabular}{|l|l|}
\hline service-LEARNING & Learning goals are primary; service outcomes are secondary \\
\hline SERVICE-learning & Service outcomes are primary; learning goals are secondary \\
\hline service learning & Service and learning goals are separate \\
\hline SERVICE-LEARNING & $\begin{array}{l}\text { Service and learning goals have equal weight; each enhances } \\
\text { the other for all participants }\end{array}$ \\
\hline
\end{tabular}

Furco developed a continuum model that has been widely used to examine individual programs as well as institutional approaches, as shown in Figure $1^{\mathrm{xxi}}$. In this model, one considers two dimensions. The first is a beneficiary, looking along an axis with end points of the providers and the recipients. The second dimension is the focus, which resides between service and learning. Similar to the earlier model, this one seeks a balance between the two elements along each dimension.

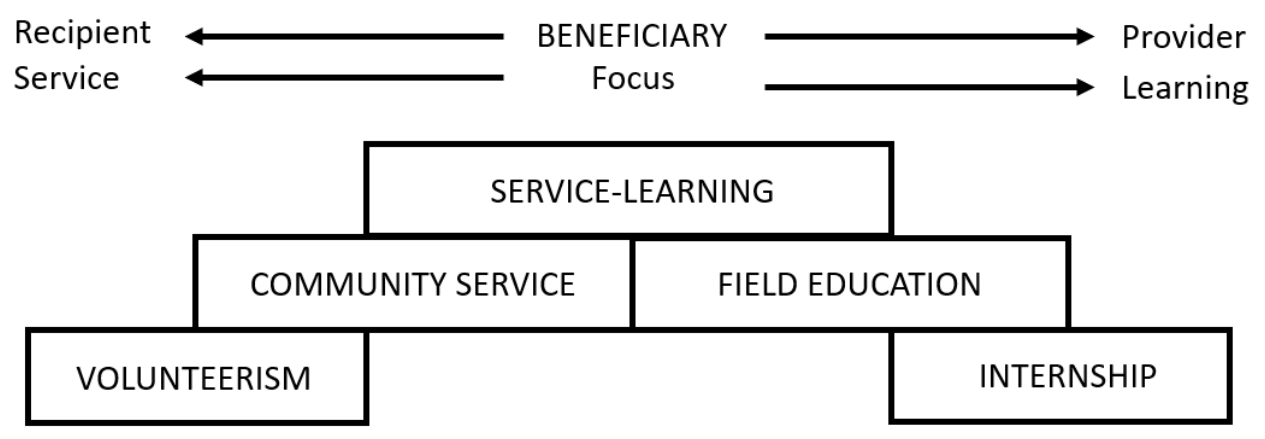

FIGURE 1

\section{Distinctions AmOng Service Programs ${ }^{\mathrm{xxi}}$}

Stanton, Giles, and Cruz presented a triangular model that sought to explore and map the diverse focus areas of many pioneers of service-learning along axes connecting the concepts of service, education, and democracy, as seen in Figure $2^{\text {xxiii }}$. Each of these terms is presented as having a contested meaning within itself and as having mutual impact on the other two. The model highlights the array of concerns service-learning programs face, as each axis represents a debate framed by the questions listed. 
International Journal for Service Learning in Engineering, Humanitarian Engineering and Social Entrepreneurship Vol. 16, No. 2, pp. 1-13, Fall 2021

ISSN 1555-9033

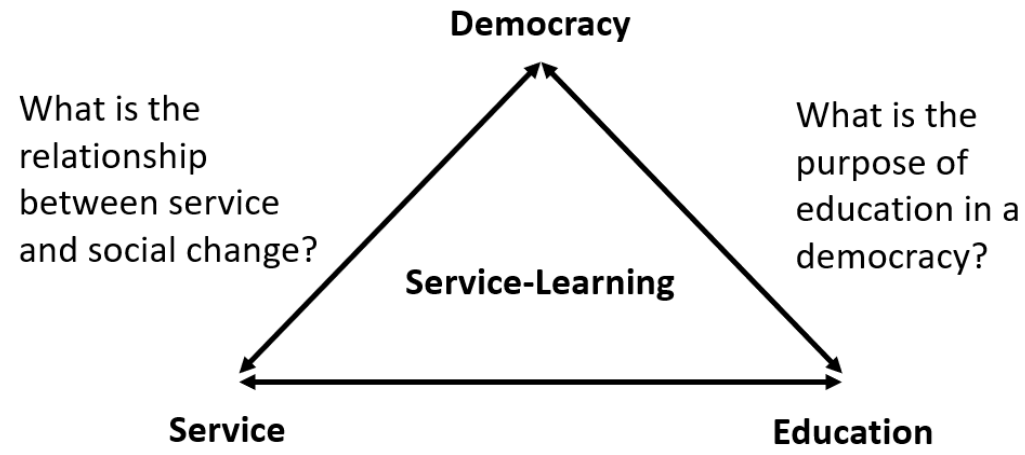

How does education serve society?

FIGURE 2

Debate Along THE AXES ${ }^{\text {xxiv }}$

While these models can be useful for project teams interested in STEM-related endeavors, they are limited in the scope of questions they seek to address and in their coverage of considerations applicable to project-based environments. The objective of the work reflected in this paper was to explore a new approach that would capture the attributes that are relevant to the project-based realm and aligned with the ideals of community engagement. We do not seek to refute the content of the previous models, but rather, expand the literature by adding additional resources to address the needs of project-based community engagement in a more targeted manner.

\section{The Difference in Project-Based Work ANd OUR Early Reflections}

Fundamentally, the conceptual difference of project-based from placement-based work is not that it simply switches out the interactive experience for the development of a deliverable, but rather, that there become two critical and district sources of value generation operating at the same time. That is, both the project process and the project deliverable, which generate, enhance, and redistribute value based on input of resources. The relationships, time, and activities that contribute to the project process can add value to many of the stakeholders by building awareness in the participants, developing connections, and helping the partners achieve their missions.

Given the growing presence of project-based community-engagement and its intricacies beyond the coverage of existing models, we explored an approach that may be more useful for engineering and STEM engagement teams. First, we produced draft intermediate graphics to illustrate the variation between placement-based and project-based community engagement, as shown in Figure 3 and Figure 4. Here, lines indicate value from the orange circle value generators transferring to the different stakeholder groups shown in yellow squares. Our intention is not to suggest any relative importance of these two sources of value. Instead, the goal is to recognize that they both exist and matter, and let the user consider and decide how they appraise the worth of different components of community engagement. We also start to see here the idea that the list of stakeholders may vary based on different model users and contexts. Examples of other stakeholders can vary by specific situation and be extensive. When the partner community is an elementary school, for example, the direct partner may be a teacher or 
International Journal for Service Learning in Engineering, Humanitarian Engineering and Social Entrepreneurship Vol. 16, No. 2, pp. 1-13, Fall 2021

ISSN 1555-9033

administrator, while other stakeholders could include the students, their parents, and the surrounding community. Stakeholders can also include administrators within a program's higher education institution such as a department head, dean, provost, or president, for instance.

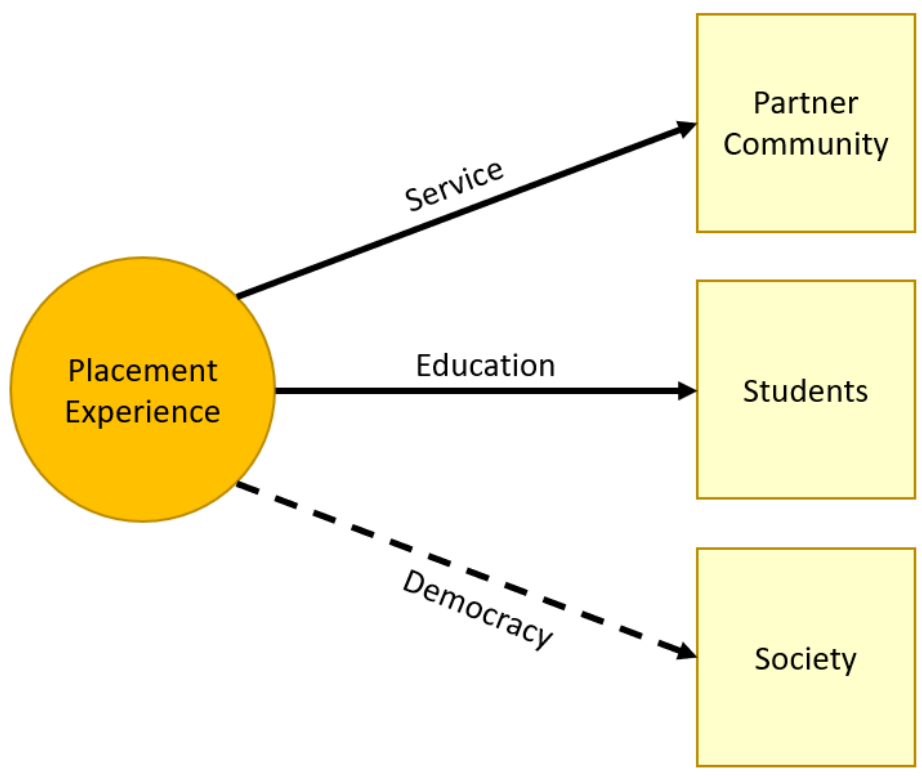

FIGURE 3

REIMAGED INTERPRETATION OF COMBINED MODELS FROM FURCO $^{\mathrm{xxv}}$ AS WELl AS STANTON, GILES, AND CRUZ ${ }^{\mathrm{xxvi}}$

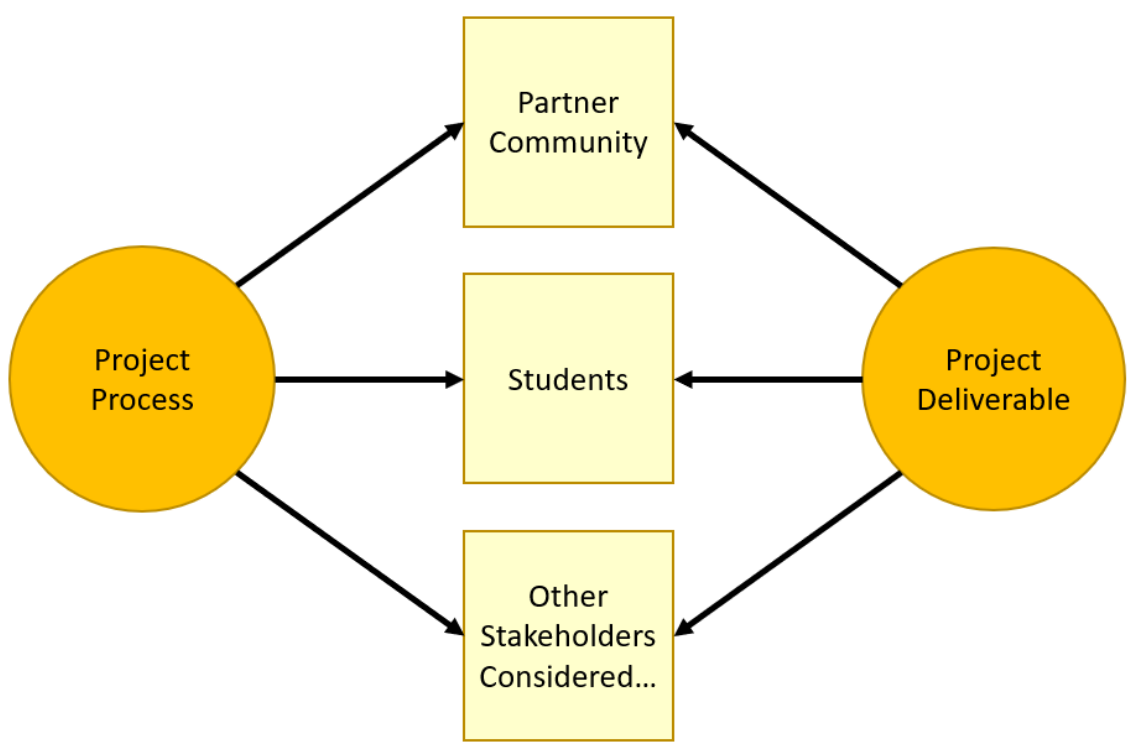

FIGURE 4

EARLY DRAFT CONCEPTUALIZATION OF Project-BASEd Community ENGagement 
These initial concepts contained their own set of challenges. First, they create an ordered list of stakeholders, which might imply importance or priority. This is counter-productive to the intent of the model and the ideals of reciprocal partnerships. This remained true to some extent even if they were rotated to list items horizontally. Second, these do not acknowledge the resources the stakeholders are bringing to the program, while also implying a one-time transfer of value. In fact, both the project process and deliverable require resources to function and exist, while teams interact with the project process over time. Third, this general layout became a bit difficult to work with when additional connection components of the model were considered. Finally, the nature of projects is that they also have a scope; a set of desired objectives, requirements, constraints, assumptions, and other elements set by the project deliverables and the work needed to produce them, which is not covered in the draft layouts shown so far.

One potential trap we also identified is the emphasis on the project's deliverable becoming an all-consuming focus of efforts. In many design courses, for example, the assessments are weighted to completion of the projects. This tendency can bleed into project-based community engagement and create challenges for building reciprocal partnerships. Figure 5 shows such a system flow where one set of stakeholders are considered to provide the input for the project and the result is sent to the end users.

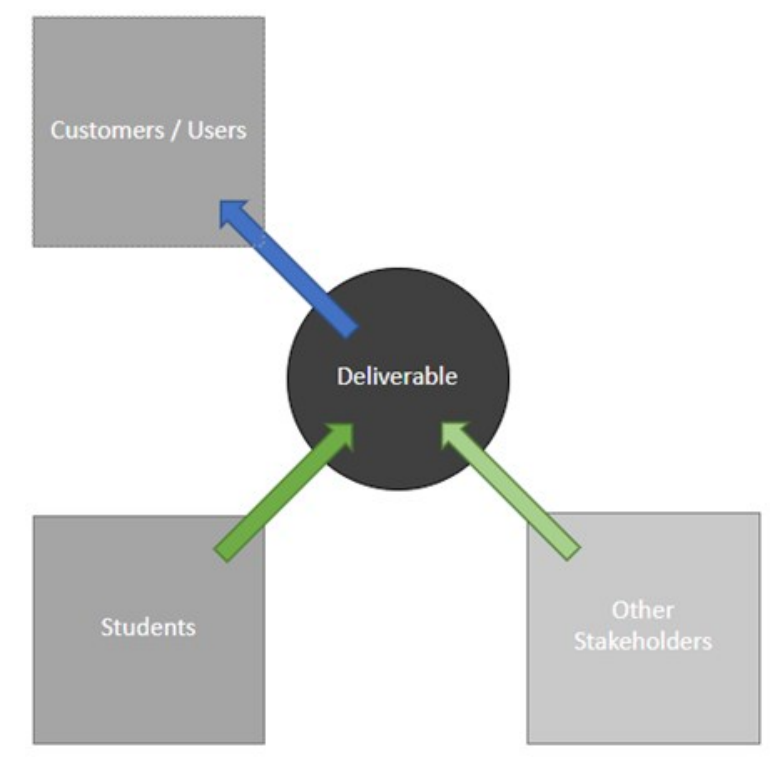

FIGURE 5

InCOMPLETE Vision of A COMMUNity ENGagement PRoJeCt

This linear approach does not account for the full picture of project-based community engagement's potential and such framing needs to be expanded. The view that the deliverable will in itself provide the value to the partner and the larger society is also incomplete and neglects the interactions, relationships, and other value created during the engagement. Decades of experience have taught this lesson to those with successful track records of engineeringrelated development and community engagement projects, such as Mike Shawcross and Mike Paddock, who argue that "[i]t is not just about the bridge, school or water system." But rather, 
"[i]t is about the project process that empowers communities and its leaders to solve their problems." can be integral for all stakeholders involved.

\section{The Model for Project-Based Community Engagement}

The results of our reflections, discussions, and iterations are shown in Figure 6. We concentrated on providing a macroscopic view of project-based community engagement to organize aspects of a program to maximize positive features and manage resources. As part of this process, we strove to make more explicit and bring to the fore the major components and interconnections to be considered in project-based community engagement. We also hope that this will increase understanding of such an approach within the larger community engagement space.

We foresee several potential uses for this model as a conceptual framework and practical tool for community engagement experiences and programs. Specifically, the visual model has been developed to facilitate reflection on program design, development, operation, and assessment. The model can facilitate intentional consideration, definition, and organization of stakeholders, project deliverables, project process, resources input, and value produced. It can also create scaffolding for users to ask and consider the questions necessary to conceptualize the full essence of project-based community engagement, while incorporating flexibility and adaptability to specific contexts. The model can be applied at the level of a project, program, system, or scholarly work.

The intent is not for authors of this paper to suggest one best or correct view in regards to the relative importance of items in the model, such as the deliverable, process, or various stakeholders. The point is that the person, program, or team that uses the model as a framework must decide for themselves what balance between items and their content they are looking for in pursuit of their goals. They can use the experience of doing so and its results to guide thinking about the project-based community engagement system at hand.

\section{MODEL COMPONENTS}

\section{Project Deliverable:}

The project deliverable is placed in the middle of the diagram and represents the physical artifact, software, system, design, analysis, or the like that is produced by the project team through the engagement experience. As mentioned before, it is the core of what makes projectbased work different than other approaches and its centrality is an acknowledgement of its significance. This location does not represent an increase in importance over the process and other aspects of the work and relationships. The intent of the model is to seek the appropriate balance and synergies within each individual context. With this model, we hope to assist teams in expanding their view to the other meaningful elements in community engagement.

Examples of physical artifact and system deliverables could include a school playground, community water supply system, greenhouse, bicycle appropriate for a person who is differently abled, or children's museum exhibit. Design and analysis deliverables can manifest as documentation, such as a construction drawings set, conceptual plans of a design which can be used to pursue further funding, or detailed reports. Software deliverables can span many levels of complexity and platforms, taking the shape of a spreadsheet to calculate energy inputs and outputs for a proposed community development, a system to track inventory throughout a 
partner's organization, or an application reporting important information among community members, for instance. Often, projects may require several interconnected deliverables across the various possible types. These would all be reflected in the deliverable component of the model.

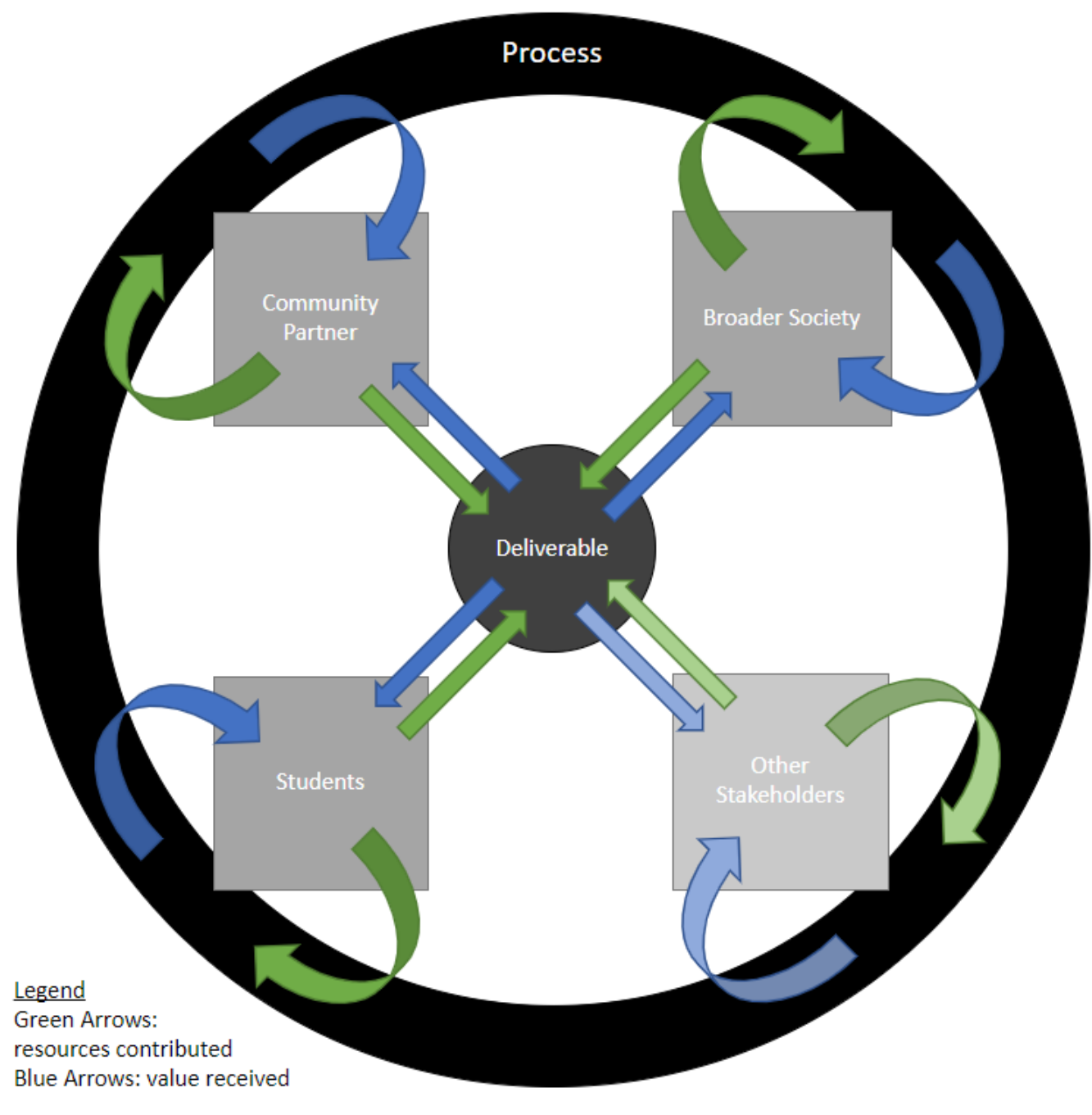

FIGURE 6

MOdel For PRoJect-BASEd COMMUNity ENGAGEMENT

\section{Project Process:}

The project process is the outer circle in the graphic that binds the stakeholders together in their shared endeavor. This contains everything that happens during the project partnership and activities, every element of the project that is not the deliverable itself, including all the phases of design, interactions between partners, relationships built and maintained, work efforts, and more. The project process embodies design epistemologies and the key ideal characteristics of the community-engaged learning pedagogy, such as reflection. Some may prefer to think of this through the lens of a pre-existing design approach, such as human centered design, but we do not 
feel it needs to be limited to any specific methodology; this may appropriately vary by application and goals of the partners involved. The process also outlines and bounds the scope of the project. The stakeholders are shown overlapping the process, as they are in a sense a part of the process itself.

There is a vast constellation of aspects that constitute the project process, with opportunities to intentionally make connections and enhance the overall experience. The model can help make these visible. Examples in this component can include interactions between partners and relationship building, site visits, collaborative visioning exercises, project progress communications, working together on deliverable assembly, and leaning about one another's backgrounds. From the design and work efforts perspective, defining the problem statement, generating specifications, iterating using prototypes, performing calculations, coding, conducting structured reflections, and crafting supporting documentation can often be just a few of the parts of the process.

\section{Stakeholders:}

The stakeholders are the grey boxes within the circle and represent those explicitly considered in connection to the program; others will inevitably be affected by the project, but are not directly included in the reflection exercise of the team. Three initial stakeholders for academic community engagement work are prepopulated in the circle, while understanding that each can be defined specifically for the application at hand. The model also has a placeholder for other stakeholders. The intent is for the people using the model to define any other stakeholders they would like to explicitly consider. For any additional stakeholder group, the user should add another stakeholder box in the circle, which is used in exactly the same way as the initial three. This process can also be used to sub-divide the initial three, if the user sees fit. The number of stakeholders can increase or decrease to the size that the team considers appropriate. Furthermore, one model feature of note is its consideration of all stakeholders in the same manner in this circular layout, avoiding any sense of hierarchy. This continues into the uniform types of connections between the stakeholders and other elements of the model. This emphasizes how all stakeholders are actively engaged as agents in the program.

While the initial three stakeholders are shown in the model graphic, engagement team stakeholders vary widely by program, institutional context, and purpose of the evaluation or reflection. Some additional stakeholders to potentially consider include: groups of people who make up important sub-sets of the community partner, portions of the wider educational institution, instructors and faculty, partner organizations, and others.

\section{Arrows:}

Green arrows moving away from the stakeholders indicate resources contributed by that stakeholder, while blue arrows moving into the stakeholder boxes indicate value received by that stakeholder. The arrows between stakeholders and the project process are shown more as circular because of the continuous give and take from the process. The arrows between stakeholders and the deliverable are shown as straight lines because these are more direct connections in a particular direction.

Example resources provided by the community partner might incorporate expertise in the context, motivations for the project, as well as the time, labor, and skills of its members. Contributions of students can include tuition funds, time, energy, disciplinary expertise, and 
diverse experience from their personal backgrounds. Broader society could potentially add funding through taxes or grants as well as provide links to potential collaborators. Value to the community partner can take the form of use of the deliverable, access to expertise from other partners, interaction with university students, and long-term partnerships. Students can see benefits such as learning related to course outcomes, bridging experiences preparing for the transition to professional work, and connecting with diverse stakeholders. The broader society may gain members more exposed to broad social issues and how they might impact them through civic engagement and application of disciplinary or design knowledge. This could also include dissemination of deliverables beyond their initial audience. Both resources and value come in many different forms, influenced by the unique structure of each program.

\section{DISCUSSION}

Throughout this modeling journey, we have refined our own views on project-based community engagement and hope the fruits of this labor will benefit others as well. Functional steps in using the model as a reflection tool include defining the explicit stakeholders, project deliverable, project process, resources input, and value produced to be considered in the conceptualization of the program. In this way, the model serves as a tool to help bring forth the thinking about and true nature of the community engagement endeavor, but it is up to the users to define their own goals and utilize the insights gained from the model in an appropriate manner. Including as many stakeholders in this effort as possible can amplify its impact. The simple act of defining the components of the model for a specific context can make them visible and facilitate intentional consideration of each of them. This also creates a platform to facilitate communication between the various stakeholder groups.

One specific use case could involve adopting the lens of reciprocity to look at the content and magnitude of resources provided and value gained by a given stakeholder group, in an assetbased approach. The relative level of these two elements may be able to reveal something about how likely the stakeholder is to continue in the partnership, affecting the program sustainability. If the balance of resources and value is reviewed across all the stakeholders, the engrained structural values of the project can come to light. If these are not currently in line with team's aspirations, such an observation provides an opportunity to re-align priorities. Furthermore, evaluating the overall system value produced relative to the overall combined resources required can reveal the comprehensive level of net benefit added through the engagement.

Another approach may be to employ the model as a tool related to project scoping, helping to define project goals, resources, constraints, and assumptions. For example, one portion of this could include compiling an accounting of the finite quantity and nature of resources available for a project. Given these, one might imagine a team has 100 tokens of value to assign to all the value arrows. How will they distribute them; what are the priorities? Then, the group could reflect on what this might mean for how one approaches the program. This can be done without having a specific project in-hand and may help in the project selection process.

The model can be used by any self-selected individual or group of people. In each case, the nature of the experience interacting with the model may change, contouring to the specific situation. The leadership of an NGO may wish to outline their engagement approach by filling in the model, which could then be employed to communicate program ideals with potential stakeholders, including students and community partners, for example. Alternatively, students 
may be asked to review a project through the framework of the model to support their reflection and approach to partner communications, as they build professional skills. The model could be addressed collaboratively between stakeholder groups from the start or it could be drafted by one party and then serve as an iterative discourse tool with partners discussing the components of the collaboration and how each aspect impacts those involved. It can be used to set expectations and standards as well as assess success and identify areas for improvement.

\section{CONCLUSION}

We believe this model represents a useful macroscopic and flexible view of project-based community engagement as well as hope that it may be used alongside other tools and resources to move the field toward more reciprocal partnerships, effective implementations, and positive outcomes. While it is rooted in the experience of community-engaged engineering, we believe it can be applied much more widely within community engagement. Indeed, with modifications to the initial stakeholders considered, it may be applicable to a very broad set of project-based activities.

This model can be used as a reflective tool in program design, development, operation, and assessment. It can make components and their connections within the engagement visible and allow intentional decision making about the weighting and balancing of elements within the experience. Community engagement is complex and dynamic. Tools that facilitate programlevel thinking can support engagement teams and scholars in a number of different capacities, including formalizing their structure of thought. We believe there could be a great benefit to the problem-based community engagement community if it were to adopt additional tailored models of the space, such as the one presented here.

\section{CALl FOR FUtURe WORK}

Future work includes applying the model to diverse programs from various perspectives to assess its applicability. The model has been used within our institution through the lens of program directors with success and new insights generated $^{\text {xxviii }}$, but wider testing will inform the model development and generalizability. Use of the model as a conceptual framework to address opportunities through contemplating how to improve project-based community engagement endeavors, reviewing case studies on specific programs, and identifying potential gaps in the existing literature is also called for. Deeper understandings of components might take the shape of exploring arguments to be made about how and why particular practical dimensions of the project process, for example, effect the overall redistribution and amplification of resources input, as they convert to value produced. Mapping research opportunities could include defining which assessment instruments are currently or could be used related to any of the arrows in the model graphic. Finally, adding supplemental materials to the model to guide engagement teams and specific stakeholders through the process would be useful.

\section{REFERENCES}

\footnotetext{
i Edward Zlotkowski, "Mapping New Terrain: Service-Learning Across the Disciplines." Change: The Magazine of Higher Learning 33, no. 1 (2001), 24-33. DOI: 10.1080/00091380109601775

ii Edmund Tsang (Ed.). Projects that Matter: Concepts and Models for Service-Learning in Engineering (Stylus Publishing Inc., 2000).
} 
International Journal for Service Learning in Engineering, Humanitarian Engineering and Social Entrepreneurship

Vol. 16, No. 2, pp. 1-13, Fall 2021

ISSN 1555-9033

iii Marybeth Lima \& William Oakes. Service Learning: Engineering in Your Community $2^{\text {nd }}$ ed. (Oxford Press, 2014)

iv "ASEE Community Engagement Division," American Society of Engineering Education, Accessed 5/3/2021, https://sites.asee.org/ced/about/

v Edward J. Coyle, Leah H. Jamieson, \& William C. Oakes, "EPICS: Engineering Projects in Community Service," International Journal of Engineering Education 21, No. 1 (2005): 139-150.

${ }^{v i}$ J. D. Thompson, \& B. K. Jesiek "Transactional, Cooperative, and Communal: Relating the Structure of Engineering Engagement Programs with the Nature of Partnerships," Michigan Journal of Community Service Learning 23, no. 2 (2017): 83-99.

vii Janet Eyler \& Dwight E. Giles. Where's the learning in service-learning? (San Francisco: Jossey-Bass, 1999)

viii Janet Eyler \& Dwight E. Giles. Where's the learning in service-learning?

${ }^{i x}$ A. W. Astin, L. J. Vogelgesang, E. K. Ikeda, \& J. A. Yee, How Service-Learning Affects Students (Higher Education Research Institute, University of California Los Angeles, 2000)

${ }^{x}$ Edward J. Coyle, Leah H. Jamieson, \& William C. Oakes, "EPICS: Engineering Projects in Community Service"

${ }^{x i}$ S. Jiusto \& D. Dibiasio, "Experiential Learning Environments: Do They Prepare Our Students to be Self-Directed, Life-Long Learners?," Journal of Engineering Education 95, no. 3 (2006): 195-205.

${ }^{\text {xii }}$ C. Zoltowski, W. Oakes, \& M. Cardella, "Students' Ways of Experiencing Human-Centered Design”, Journal of Engineering Education 101, no. 1, (2012): 28-59.

xiii W. T. Monroe, M. Mailander, \& M. Lima, "Focus on Experiential Education: A Freshman Engineering Program in Biological Engineering," International Journal of Engineering Education 22, no. 6 (2006): 1129-1138.

${ }^{\text {xiv }}$ William Oakes, James Huff, Carla B. Zoltowski, \& Devendra Canchi, "Impact of the EPICS Model for Community-Engaged Learning and Design Education," The International Journal of Engineering Education 34, no. 2 (2018): 734-745.

${ }^{x v}$ L. Piket-May \& J. Avery, "Service-Learning First Year Design Retention Results," ASEE/IEEE Frontiers in Education Conference, (2001)

${ }^{\text {xvi }}$ A. R. Bielefeldt, K. Paterson, \& C. Swan, "Measuring the Value Added from Service Learning in Project-Based Engineering Education," International Journal of Engineering Education 26, no. 3, (2010) 535-546. Page 542.

${ }_{\text {xvii }}$ H. M. Matusovich, W. Oakes, \& C. B. Zoltowski, "Why Women Choose Service-Learning: Seeking and Finding Engineering-Related Experiences," International Journal of Engineering Education 29, no. 2 (2013) 388-402.

xviii Janet Eyler \& Dwight E. Giles. Where's the learning in service-learning?

${ }^{x i x}$ R. Sigmon, "The Problem of Definition in Service-Learning," In Sigmon et al., The Journey of Service-Learning (Council of Independent Colleges, 1996)

${ }^{x x}$ R. Sigmon, "The Problem of Definition in Service-Learning"

${ }^{x x i}$ Andrew Furco, "Service-Learning: A Balanced Approach to Experiential Education," In B. Taylor and Corporation for National Service (Eds.), Expanding boundaries: Serving and learning (Corporation for National Service, 1996): 2-6.

xxii Andrew Furco, "Service-Learning: A Balanced Approach to Experiential Education"

xxiii Timothy K. Stanton, Dwight E. Giles, \& Nadinne I. Cruz. Service-Learning: A Movement's Pioneers Reflect on Its Origins, Practice, and Future (Jossey-Bass, 1999)

xxiv Timothy K. Stanton, Dwight E. Giles, \& Nadinne I. Cruz. Service-Learning: A Movement's Pioneers Reflect on Its Origins, Practice, and Future

${ }^{x x v}$ Andrew Furco, "Service-Learning: A Balanced Approach to Experiential Education"

xxvi Timothy K. Stanton, Dwight E. Giles, \& Nadinne I. Cruz. Service-Learning: A Movement's Pioneers Reflect on Its Origins, Practice, and Future

xxvii Mike Paddock. Bridging barriers: How a Community Changed its Future with Help from Engineers Without Borders USA Volunteers (Orange Hat Publishing, 2020): 277-278.

xxviii Paul A. Leidig \& William C. Oakes, "Engagement in Practice: Project-Based Community Engagement Model Preliminary Case Studies" ASEE Conference, (2021) 